\title{
The man who would be worth billions: Vincent Pericard, migration and mental illness
}

This paper builds on the limited body of work that currently exists in respect of sports work and mental illness. It does so by drawing on the case of Vincent Pericard, a Cameroonian born, French international footballer who was described in a 1999 television documentary as 'The man who will be worth billions', but who, following a poorly managed transfer between Juventus and Portsmouth, retired from the game at the age of 28, having being diagnosed with depression. Based upon a series of interviews conducted with Vincent over an eight-year period, the intention of this paper is two-fold. Firstly, I analyse the conditions of Vincent's transfer from Juventus to Portsmouth. I examine how a loss of status and diminished sense of self, coupled with a range of other challenges specifically related to Vincent's migration, acted as triggers to the initial development of his depression. Secondly, I analyse Vincent's working environment in England. In this section, I draw on the work of Goffman to show how Vincent was forced to conceal the deterioration of his mental health - something that ultimately contributed to a worsening of it. These analyses are used to illustrate two things: 1) the potential mental health consequences that can occur when the international transfers of foreign players are not managed effectively; and 2) the negative effects a player's club environment can have on their mental health, if no suitable outlet exists for them to be able to discuss it.

Keywords: Football, migration, mental illness, depression, Goffman.

Richard Elliott (2020): The man who would be worth billions: Vincent Pericard, migration and mental illness, European Journal for Sport and Society, DOI: 10.1080/16138171.2020.1823690 
In 1999 French filmmaker Julien Courbet produced a documentary entitled 'L'homme qui valait des milliards', or 'The man who will be worth billions'. The film featured a 17-year-old Cameroonian-born French footballer named Vincent Pericard, a striker who had emerged as a potential star at French Ligue 1 club Saint Etienne. Vincent had joined the French side as a six-year-old boy in 1988 and whilst he only made two first team appearances for his boyhood club, playing in France's top division and for French national youth teams brought him to the attention of one of the worlds most famous football clubs, Italy's Juventus. Vincent made his debut for the Serie A side in 2002 in a Champions League match when he came on as a $61^{\text {st }}$ minute substitute in a game against Arsenal of the English Premier League. When Vincent took to the pitch in that first match his teammates included some of the worlds most highly recognisable stars; players such as Gianluigi Buffon, Alessandro Del Piero, Edgar Davids and David Trezeguet. During this period in his life everything appeared bright for Vincent; indeed it could be argued that he had the 'world at his feet' (Magee and Sugden, 2002). Yet, just a few years later, his career was over with Vincent never having ascended to the lofty heights that Courbet's documentary had predicted.

Vincent was never given the opportunity to establish himself at Juventus. Indeed, his Champions League appearance was the only one he ever made for the Club's first-team. In July 2002 he was suddenly transferred to Portsmouth FC, a team who, at the time, were playing in England's second division. Difficult circumstances and a poorly managed transfer to the English club meant that life in England was very challenging for Vincent, and he struggled to settle and adjust in his new environment. Having never established himself in Portsmouth, Vincent left on a free transfer in 2006 to join Stoke City FC. After failing to settle again, Vincent was sent out on a number of loan periods. Before long, he found himself languishing in the lower divisions of English league football. After a short spell in non-league football, Vincent Pericard, the man who would be worth billions, found himself out of the game altogether. He retired from professional football, aged just 28, in February 2012.

Arguably, Vincent's story is not entirely unusual in the context of professional football. For the most part, careers in the game are short and it is 
only a very small minority of players who ever become established professionals with the capacity to gain celebrity status and accrue significant wealth (Roderick, 2006a). For the majority of professional footballers, career uncertainty is a reality of everyday working life. As Roderick (2006b, p.245-246) puts it:

Uncertainty is central to the lived experiences of players, for whom career advancement and attainment are never secure. Professional footballers' work histories are characteristically unstable and short-term; players gain quickly an understanding of the uncertainty of the marketplace, the limited tenure of average contracts, the surplus of potential quality labour and their own vulnerability to workplace injury and ageing.

For players who migrate from one country to another to ply their trade, there are additional layers of complexity. Rarely is migration from one place to another simple or straightforward. It can often be a highly stressful experience that is fraught with challenges (Bhugra and Becker, 2005; Bhugra et al, 2014; Sharma and Jaswal, 2006). This was the case for Vincent, who had to cope not only with all of the uncertainties that a career in professional football brings, but also all of the challenges that working and living abroad present. Over time, both would have a significant effect on his mental health and, subsequently, the trajectory of his career.

During 2008, after failing to settle at Stoke City FC, Vincent was referred to a psychologist who diagnosed him with depression. By this point, Vincent had, for much of his employment in England, been suffering from a fluctuating but largely depressive mood state, periods in which he was unable to think or function properly, bouts of fatigue, repeated feelings of worthlessness and, at its worst, thoughts of suicide - all markers of depression as defined by the Diagnostic and Statistical Manual of Mental Disorders (DSM-5) diagnostic criteria (APA, 2013). Arguably, the onset of this depression had been triggered as a result of the circumstances of Vincent's initial transfer to England and a specific series of challenges that he struggled to cope with as a foreign player. A subsequent and ongoing deterioration of his mental health occurred as a result of having to adhere to the normative modes of conduct identifiable in his workplaces; places where, for a number of reasons, Vincent found it impossible to seek help or reveal to others how he was feeling. 
Arguably, Vincent's case is an interesting one in the newly emerging context of sports work and mental illness. Whilst issues relating to sports work and mental illness have received greater media coverage in recent years (see DeHaney, 2013, for example), there are still very few academic studies that have sought to examine the ways in which mental illness, and depression particularly, can affect an elite athlete's career; as a result, empirical studies are rare (Frank et al, 2015; Gouttebarge et al, 2015; Hughes and Leavey, 2012). The dearth of research into the prevalence and impact of depression in elite sport likely reflects the focus on more acute aspects of sports performance such as anxiety, and a lack of attention to elite sports workers by psychiatrists. Additionally, in the few cases where research has occurred in this area, the focus has, to this point, remained on home-grown workers; that is, workers who are employed in their country of birth (see, for example, Roderick and Gibbons, 2015). No study has yet sought to show how the complex interplay of psycho-social factors that can lead to a depressive state can be exacerbated within the unique set of circumstances in which elite migrant athletes play out their careers and their lives.

Taking the above into account, and using Vincent's transfer to, and subsequent employment in England as a case study, the intention of this paper is two-fold. Firstly, I analyse the conditions of Vincent's transfer from Juventus to Portsmouth. Here I examine how a loss of status and diminished sense of self, coupled with the effects of a poorly managed international transfer, acted as triggers to the initial development of his depression. Secondly, I analyse Vincent's working environments in England. In this section, I draw on the work of Goffman (1959, 1963) to show how Vincent was forced to conceal the deterioration of his mental health - something that ultimately contributed to a worsening of it. These analyses are used to illustrate two things: 1) the potential mental health consequences that can occur when the international transfers of foreign players are not managed effectively; and 2) the negative effects a player's club environment can have on their mental health, if no suitable outlet exists for them to be able to discuss it. Combined, the findings from this paper have important implications for the management of the international transfers of 
foreign players, and the disclosure of mental health issues in the working environments in which elite footballers ply their trade.

\section{Method}

The data presented in this paper have been generated from a range of qualitative interviews conducted with Vincent himself over a number of years. My relationship with Vincent began in 2010 when I was introduced to him by a mutual acquaintance at Portsmouth FC who was aware of my work as it relates to migration and professional football, and Vincent's career history. Vincent was in the process of attempting to establish a company focussed on addressing the challenges faced by foreign footballers transferring to, and playing for, clubs in England, and it was suggested that we should meet. Vincent and I quickly built a rapport, and we met on a number of occasions to discuss aspects of his business and his own experiences as a foreign player in England. As our relationship developed, so Vincent opened up more about his life and career, and the depression that, in his opinion, had forced him out of the game. After having known Vincent for a number of years, I asked if I could formally capture data in respect of his experiences through a series of interviews.

Methodologically, my intention was to give voice to Vincent's experiences. I wanted to allow him to tell the story of his mental illness in his own terms because I was acutely aware following our informal conversations that in the past, and in common with other sufferers of mental illness, his feelings had been 'marginalized, shunted off to the side, or discounted altogether' (Karp, 2017, p.2). Indeed, it became apparent from a very early stage in our relationship that Vincent wanted to talk about the problems that he had faced, in part because he clearly didn't want other foreign players to suffer the same difficulties that he had, but also because I sensed speaking to his illness somehow formed part of the rehabilitation process. This would make sense in the context of McMahon and Penney's (2011) work, which explores the ways in which participation in interviews can have an emancipatory dimension that specifically enables participants to gain clarity in relation to events, experiences and emotions that they may not have previously achieved. As the interviews went on, I became 
aware of the increasing clarity and confidence with which Vincent spoke about the events and emotions that he had previously experienced.

Whilst Vincent gained confidence and revealed more about his experiences as the interviews went on, he made it clear, from our very first meetings, that nothing he said should ever be viewed as confidential or somehow 'off the record'. In some ways this created something of an ethical dilemma. Being placed in the privileged position of being gifted borderless access to such personally sensitive information opened up the possibilities, as it does in much mental health research, of exploitation, therapeutic misconception and misrepresentation (Hewitt, 2007). As such, it was imperative that a series of recognised guidelines were followed as part of the data collection process. For the purpose of this study, these guidelines were drawn from the 'National Institute for Health Research (NIHR) Good Practice Guidance for Involving People with Experience of Mental Health Problems in Research' (2013). These guidelines ensured that Vincent was aware, before any formal data collection phases began, of what was being sought, his role in the project, the expectations of the study, and how the data would be used. Concomitantly, and as part of the guidance, institutional ethical approval was sought.

In order to capture the richest data set possible, data collection took place over a period of eight years. In building the schedules for the six formal qualitative interviews that would take place during this period, I spent time talking with Vincent informally and, on some occasions, and with permission, observed his interactions and conversations with others. These observations occurred as part of meetings related to Vincent's new company and a number of University visits to deliver guest lectures that occurred once or twice a year during the period of data collection, in a range of settings (stadiums, company offices, hotels, lecture halls and teaching spaces) and which included sports psychologists, player liaison officers, other players, members of the media, academics and students. The intention in adopting a longitudinal approach was to slowly introduce new elements to conversations and interactions over time as I learnt more about Vincent, and to avoid the data collection process becoming like a formal interrogation. Additionally, the approach was adopted to allow for 
the building of rapport and trust between Vincent and myself. It was designed to ensure that the developing relationship between Vincent and I was not an oppositional one but, rather, one in which the process of data collection was negotiated with Vincent. This was an important distinction that was made in the context of relational ethics, an approach that takes account of the centrality of responsibility for the other (Pollard, 2015). During the period of having known Vincent, I have compiled a data set of interview transcripts, notes and observations that form the basis of the data presented herein.

The data were analysed using a reflexive thematic analysis (Braun and Clarke, 2019). This approach is well suited to the constructionist epistemology that is applied in this study, as it focuses on the ways in which meanings and experiences are socially produced. Within a constructionist framework, a reflexive thematic analysis does not focus on individual motivations. Rather, it can be used to make sense of the sociocultural contexts and structural conditions that frame the individual accounts that are provided (Braun and Clarke, 2006). In practice, the approach requires the researcher to search across a data set to find repeated patterns of meaning. This is done through a number of stages that include: familiarisation with the data following transcription, initial coding, searching, reviewing and defining themes, and writing up (Braun and Clarke, 2006).

Various themes emerged from the data. Most notably, these related to the problems that Vincent faced in coping with his transfer and the demands of migration, the challenges reflective of employment in the English football environment, and, connected to that, the effects of having to homogenise his behaviours to meet the specific demands of that particular workplace. Not unsurprisingly, these themes were tightly knitted into Vincent's story. As such, and in keeping with other research of this nature, whilst the sub-sections that follow have been developed on the basis of the themes, they also flow logically through Vincent's story. This is to give some sense of the themes, but also their temporality within the narrative of Vincent's career and his deteriorating mental health. 


\section{The Transfer}

On March 20 2002 , Vincent Pericard made his first-team debut for Juventus, when he came on as a $61^{\text {st }}$ minute substitute in a Champions League match against Arsenal. Whilst he didn't know it at the time, this appearance would mark the pinnacle of his career as a professional footballer. Shortly afterwards, Vincent was transferred to Portsmouth FC, a team that were, at the time, situated in the English Football League Championship - England's second division. To the outsider the transfer appeared to come out-of-the-blue. Vincent seemed to be on the cusp of establishing himself in the Juventus first-team and seemed happy. Yet now, all of a sudden, he had been transferred to a relatively unfashionable second division team in England.

The reality of Vincent's sudden transfer was that he had effectively been 'expelled' (see Sugden and Magee, 2002) from Juventus; that is, he had been forced to migrate to England as a result of inadvertently upsetting one of the club's directors. He recalled:

One night with my other two French friends, we were at home and we were bored and one of them suggest "oh let's do something tonight", so like most people we say we'll go and have a drink. So I suggest "why don't we text our Italian teacher", to see if she wants to have a drink ... Ten minutes later I get a phone call. I pick up the phone and the guy on the other ends says "how dare you text my girlfriend". That guy was one of the Juventus directors. He said "you three, in my office tomorrow morning". When we get there in the morning he literally looked at us and said "you're going there, you're going there and you're going there", no discussions. So that's how I ended up in Portsmouth. It's not because of my football, it's not because of anything else; it's because I sent the wrong text at the wrong time and I'd never heard of Portsmouth. It never crossed my mind to come to England.

The circumstances in which Vincent's transfer to Portsmouth occurred and the clubs subsequent management of it would have a lasting effect on his mental health and his career from this point on.

Uncertainty and instability are occupational hazards of a career in professional football (Roderick, 2006b). Vincent experienced this when he was suddenly transferred to Portsmouth. As he put it, when recalling the transfer: “everything was agreed without my ever having a say. I couldn't do anything. I 
just had to sign. I had no control." This lack of agency in the transfer had a significant affect on Vincent's mood state. This became apparent when he recounted how he felt at the time: “when I went from Italy to England, I wasn't happy. So obviously, that kind of set the mood straight away." Involuntary or 'forced' migration has been identified as a significant risk factor in the development of mental illness for migrants. Scholars have argued that this type of migration is likely to test a migrant's psychological stamina more so than voluntary migration and can lead to a range of mental disorders, including stress, anxiety, depression and post-traumatic stress disorder (Bhugra et al, 2014).

Vincent also struggled to come to terms with his departure from Juventus because he saw his move to Portsmouth as a backward step in his career. Research shows that most transfers in football occur in this way, that is they are lateral or downward moves to clubs of lower status (Roderick, 2012). It also shows that when players move to a team that they perceive as being inferior to their previous one, they can frequently experience a loss of status and/or diminished sense of self. According to the DSM-5 criteria (APA, 2013), both are markers for the development of depression (APA, 2013).

To exacerbate the deterioration in Vincent's mood state, the practicalities of his transfer to Portsmouth were also problematic and stood in contradiction to his previous international transfer from St Etienne to Juventus that had occurred just a year earlier. In respect of this transfer Vincent recalled:

[Juventus] were very professional; they gave me a flat, they gave me a car, and I received my first paycheck, which was nice to have. They also gave me a tutor so that I could learn Italian. So I had everything that I needed to settle.

Vincent's transfer to Portsmouth was not managed in the same way, however, and the club offered little social or occupational support when he arrived in England. He recalled:

I couldn't speak a word of English; I couldn't communicate ... they put me in the hotel for four months, which was draining after a while. It was kind of depressing eating the same food everyday, being by yourself everyday, not knowing anyone ... I wasn't guided in terms of the English lifestyle 
and the drinking culture. I wasn't guided financially. I was only 18 and had no idea about England, but they just expected me to play.

Being able to speak the language and to understand aspects of the culture in a host country have been identified as key factors in the adjustment, settlement and experience of migrant workers (Ward et al, 2001; Weedon, 2012). For Vincent, these things had to be learnt through a process of "trial and error", as he put it. In Vincent's case, lacking competency to speak and understand English made the most basic day-to-day tasks very difficult. Additionally, struggling to understand the culture whilst living out of a hotel room had an isolating effect that exacerbated a sense of loneliness. Over time, Vincent began to experience a sense of loss in respect of his former self and the familiar cultural environments in which his life had been framed. Like other migrant sports workers (see, for example, Agergaard, 2014; Bourke, 2003; Elliott, 2014, 2015; Carter, 2011; Magee and Sugden, 2002; Maguire, 1996; Maguire and Stead, 1998; Molnar, 2010; Richardson et al, 2012; Stead and Maguire, 2000; Weedon, 2012), he found it very hard to settle in a new and unfamiliar place where social and occupational support was limited (Gouttebarge et al, 2015).

The inability to settle in Portsmouth resulted in a continued deterioration in Vincent's mental health. He recalled how his first months in Portsmouth were his worst in football. His struggles off the pitch were manifested by a significant loss of physical form on it in training and matches. As a result of his deteriorating mental health, Vincent lost the ability to perform at levels that he had previously been used to. He also began to suffer from bouts of fatigue that would further hamper his performances. When recounting his feelings during this period, Vincent commented: "I was thinking, I don't want to go to training, I'm not worth it". Indeed, Vincent struggled to such an extent that he came to believe that he "couldn't play football anymore," something that he believed his teammates were quick to pick up on. Whilst Courbet's documentary had not been aired outside of France and Vincent's Portsmouth teammates were unaware of the moniker with which he had been bestowed, he was acutely aware of the expectations they had for a player who had been transferred from one of 
the worlds most successful football clubs. Arguably, this increased the sense of pressure that he was feeling as his performances deteriorated.

Although research into the international transfers of migrant sports workers remains relatively limited, what scholars have shown is that the process of moving from one country to another can often leave migrants feeling isolated (particularly if they travel alone - which Vincent did), unable to communicate effectively and, ultimately, dislocated from important social networks (Fry and Bloyce, 2017). It shows how they may, on some occasions, encounter a sense of loss in respect of familiar environments, in addition to confusion, rejection, selfdoubt, personal insecurity and a decreased sense of self-worth (Bourke, 2003; Molnar, 2010; Weedon, 2012) - all risk factors in the development of mental health issues (APA, 2013; WHO, 2012; Wood et al, 2017). Vincent was exposed to all of these forces during his transfer from Juventus to Portsmouth, and his exposure to them triggered a depressed mood, an inability to think or function at levels that he had previously been used to, bouts of fatigue, and feelings of worthlessness - all diagnostic markers for depression according to the DSM-5 criteria (APA, 2013).

Concomitantly, however, Vincent believed that whilst the conditions of his transfer acted to initially trigger the onset of his depression, the problems associated with his deteriorating mental health were exacerbated within the specific structures of his working environments. Indeed, Nesti (2010) argues that the structures of professional sport are such that they can create the conditions for a range of social, emotional and psychological problems. Vincent believed that this was the case in his working environments in England, because he saw no outlet through which he could discuss the challenges he was facing. As such, understanding the environment, and the 'performance' that Vincent was required to stage within it, is a crucial component in understanding the ongoing deterioration of his depression. The next section of the paper explores this idea in greater detail. 


\section{The football environment}

Accounts of the internal workings of English professional football environments are rare. This is likely a reflection of the 'closed-door' nature of the industry and specifically those highly protected components of this particular workplace - the training ground and the dressing room. Indeed, even back in 2002, Magee and Sugden, in their analysis of the migrations of professional footballers, described professional football environments as 'impregnable' (p.423). If anything, access to the inner sanctums of these places and the workers that can be found within them has become more difficult since that time. That said, it is possible to identify a very small number of studies that provide critical insights into this highly secretive world. Martin Roderick, for example, has provided some of the most comprehensive accounts. As a former professional player (for Portsmouth FC) turned academic, he describes English football as a ruthless, authoritarian and hyper-masculine workplace where aggressive and masculine identities are constructed and celebrated (2006a, 2006b, 2012). Another former professional player turned academic, Seamus Kelly (2016, p.79), identifies similar themes within the 'macho culture' of English professional football. He describes an environment in which performance scrutiny is constant and expectations are high. Failure, he argues, is not tolerated well.

Vincent became aware of the normative values evident in English professional football environments as soon as he arrived in Portsmouth. As part of his socialisation, Vincent quickly learned to conform to the dominant and hyper-masculine cultural practices and behaviours of the English football workplace that included dressing-room banter (teasing/mockery exchanged between players or other club staff), drinking and promiscuity (Kelly, 2016). Ultimately, these forces became a normative form of control for Vincent and compliance shaped the culture of his working environment. Self-preservation or 'survival' (Wood et al, 2017, 122), secured only by successfully navigating the challenges of ruthless competition in training and matches, further shaped his workplace attitude (Roderick, 2006a). He drew attention to this aspect of the environment a number of times. On one particular occasion, he remarked: 
Everyone's got their own purpose, which is to improve on their existing contract. It's not "we're going to play as a team", it's "I've got one year", "I've got two years", "I'm going to do my best during that time to get my next move" and that creates separation ... Everyone was there to look after themselves and I realised that you cannot show weakness because everyone is looking at you to show a sign of weakness so that they can take your place. So you have to go to training and put a brave face on. Even if you're not happy you just have to stay strong and keep going.

Vincent's perceptions of his working environment illustrate how the pressures to conform to the normative attitudes of the work place coupled with contractual uncertainty consumed his life and that of his peers (Roderick, 2006b).

In conforming to the normative attitudes of his workplace, Vincent learnt very quickly that any manifestation of weakness, be that physical or mental, could be harmful to the legitimisation of his place. He also recognised, as others who have examined elite sports environments have, that there was a considerable stigma attached to mental ill health (Carless and Douglas, 2019). As a result, Vincent felt unable to discuss how he was feeling since moving from Juventus, or the more specific challenges he was facing as a consequence of his migration, such as loneliness, dislocation or confusion. As he put it:

They wouldn't have understood. That's just how it is. You have to show how resilient you are, that you're a man; you can't just give up, you have to get tough ... Whenever the manager told me to "get on with it" I would try to just get on with it because, at the time, I thought being strong was what you were supposed to do.

With no outlet to discuss the challenges he was facing, Vincent was forced to hide the problems and their effects on his mental health, and instead presented what he believed was a socially acceptable work ethic via a carefully crafted presentation of self.

Throughout his career in England, Vincent learnt to become a 'skilled manipulator' (Kelly, 2016, p.80) of his workplace self. He recognised that he had to conceal his true feelings so as to avoid the stigma that might be associated with the manifestation of behaviours not deemed compatible with the dominant normative values of his workplace (Goffman, 1959, 1963). Vincent had to carefully manage information about his deteriorating mood state through the 
process of what Goffman (1963) calls 'passing'. In Vincent's case, this meant ensuring that any manifestation of negativity effectively disappeared from sight of those around him; only he, as passer, knew about his true feelings. Concomitantly, Vincent also engaged in a process of 'covering' (Goffman, 1963), where he engaged in a range of behaviours to conceal his developing depression so as to appear like a 'normal' athlete as opposed to a 'stigmatised' one (Goffman, 1963). The processes of passing and covering compelled Vincent to engage in a complex dramaturgical performance that was designed to control the impressions that his colleagues had of him. Vincent had to convince his manager, coaches and teammates that he possessed the attributes to contribute to the goals of the club effectively, even though his increasingly depressive state may have meant otherwise (Roderick, 2006a).

Key to the success of Vincent's performance was the recognition that certain behaviours should be accentuated and others suppressed. Vincent was expected, for example, to over-communicate the characteristics associated with what might be called 'good attitude' (Roderick, 2006a, p.43). He was expected to demonstrate an excellent work ethic and unquestioning commitment to the team. Moreover, he was expected to present these qualities as components of a strong and tough personality or 'hard front' (Kelly, 2016, p.80) compatible with the machismo of professional football. Additionally, and critical for Vincent to gain increased favour in terms of managerial preference, was the requirement to demonstrate a positive frame of mind. Thus, the negative and depressive emotions that he was feeling had to be suppressed and under-communicated; these emotions were simply incompatible with the characteristics of good attitude and could be viewed as highly problematic in the professional football workplace (Wood et al, 2017).

The display rules, or behavioural norms, that exist in English professional football clubs dictate that negative emotions should be suppressed (Grandey, 2000; Lee Sinden, 2012). To exhibit these emotions would be to concede weakness in an environment where failure is rarely tolerated (Pike, 2019). This was a challenge for Vincent who risked being exposed to 'discreditable stigma' (Goffman, 1963) if his true mood state was made known. This meant that 
Vincent found it impossible to reveal to others how he was feeling as he became increasingly depressed. As he put it:

It's simply because the nature of the game dictates that we can't show any weaknesses within the dressing room. It's not acceptable that you raise your hand and say "gaffer, I'm not feeling well, I'm depressed" because we would be chopped and might not even be on the bench ... If you don't play, they don't renew your contract and you're out of a job. It's the football environment that doesn't give you the time and inclination to address any weaknesses like depression.

Paradoxically, it might be argued that the suppression of emotion in football environments is something to be celebrated. After all, those players who are able to avoid showing negative emotions and who are described as showing enhanced levels of 'mental toughness' (Jones et al, 2002) are likely to be ranked more highly in the minds of their peers (Bauman, 2017; Lee-Sinden, 2010).

Vincent had to avoid at all costs passing any facts that could discredit, the impression that his performance fostered. As such, he had to carefully manage any undisclosed discrediting information about his self (Goffman, 1963) and cover any facts about his condition that could potentially be harmful to perceptions of him, as these might be regarded as 'destructive information' (Goffman, 1959). He made reference to conforming in this way:

When things were going bad I would be on autopilot. I just had to smile, puff out my chest, put on that everything was okay and go through the motions. Otherwise, you can guarantee that the manager would pick up on things.

Conforming in this way is common practice in elite sports environments where sports workers disengage, cover, suppress and under-communicate what might be perceived to be negative emotions in order to avoid being stigmatised in ways that run counter intuitively to the normative modes of conduct in these types of environments (Lee-Sinden, 2012). As Vincent put it:

The logic is it's a competitive game and you have to win. If you don't win, you don't get the money, you don't get the trophy, you don't get the TV rights. And the manager, his task is to win games - therefore he has to put the best team on the pitch. Having a weak link as a player is counterproductive. Add to the fact that your contract is limited. As 
players we need to do as much as possible to show good values that will be approved. Having a weakness is not compatible.

Whilst Vincent perceived the covering of his increasingly depressive state as a necessity to demonstrate mental toughness and good attitude, what he failed to appreciate at the time were the long-term mental health consequences of his actions (Lee Sinden, 2010). The next section of the paper explores this problem.

\section{The effects of emotional conformity}

Research has shown that, over time, forced emotional control can have a detrimental effect on an athletes mental health when they find themselves unable to homogenise their emotions to the social context of elite sport and may seek alternative emotional outlets, such as alcoholism, drug use or other selfdestructive behaviours (Lee Sinden, 2012; Palmer, 2019). The demands of his working environment in England were such that Vincent had to consistently invest in his own 'emotional labour' (Hochschild, 1983) - a process in which he was compelled to manage feelings and expressions to fulfill the emotional requirements of his workplace - as he sought to cover his depression. It was crucial that Vincent's performance matched the display rules of the environment and that his presentation of self was compatible with the normative values of club culture. This was highly problematic, however. Over time the stress placed upon Vincent to behave in accordance with the display rules and sub-cultural values of his workplace, coupled with the risk of being exposed to 'discreditable stigma' (Goffman, 1963) became mentally exhausting (Mummery, 2005). The contributory psychological effects of this exhaustion were clear for Vincent. When recalling how he would feel as he left the training ground, he commented:

I would get up in the morning knowing that I only had to put the act on for two hours from 10am to 12noon. But as soon as I was finished, I would get into my car, I would be like (at this point Vincent drops his head and exhales deeply), I'm just going to go home and play Playstation.

Vincent went on to recount how he felt once he had returned home:

I felt relieved. I felt like I am back in control. I felt like I am safe because there's no one about to judge me, there's no one looking at me, there's no one who's going to criticise me. It's just me, myself and I, in my own space 
and that felt like a massive relief. When I got home and closed the door it felt amazing because it was just me and I was out of the stress ... I didn't have to keep it up, which required lots of energy, I could just close my eyes and switch off.

Arguably, Vincent was leading a double-life. One in which he attempted to present a socially acceptable work-self that accentuated the characteristics deemed compatible with the professional football environment, whilst, at the same time, he was trying as best to cover his depression and was vulnerable; desperate to escape the confines of the performance and the constant scrutiny and risk of stigma that came with it.

It can be argued that Vincent was struggling to cope with the 'problem of authenticity' (Roderick and Gibbons, 2015). That is to say that he was engaged in a constant battle with his own self-identity, one where his private and public selves seemed incompatible. At work Vincent felt that he could never discuss his mental health for fear of the stigmatisation that might occur. Instead, his energy had to be directed into his performance and the ongoing concealment of his depression.

The constant strain as he attempted to adhere, whilst simultaneously covering his true feelings had, over time, a catastrophic effect on Vincent's mental health. As he put it: "I stopped caring. I'd just go home and lock myself in. I didn't want to speak to anyone. I'd given up. I had no motive to carry on." At his lowest point Vincent even considered the possibility of suicide:

I locked my door, sat for an hour on the sofa just being numb because I couldn't think. I had to do something to get me out of that numbness. I was about to go to sleep and I thought, "I'm going to take sleeping pills and if I don't wake up, never mind". I just wanted to go to sleep and see what happened. I wanted to leave.

Fortunately, Vincent never acted on his suicidal tendencies. He realised, over time, the problematic nature of his behaviours. As he put it:

If you keep it inside you accumulate that feeling, then it stays until the day it breaks you. That's what happened to me ... now I realise that was totally the wrong thing to do. It was making it worse, not better. 


\section{Conclusion}

Vincent Pericard had to deal with a number of challenges during his transfer from Juventus and subsequent employment in England. Arguably, these included all of the pressures that a career in elite sport inevitably brings, plus, as this paper shows, a range of additional complexities related to international transfer and acculturation in a foreign country. Vincent's transfer from a leading European club to a second division one in England, particularly in such unfortunate circumstances, meant that when he arrived in England, he was potentially already suffering from a diminished sense of self. The subsequent lack of support provided upon arrival in Portsmouth meant that isolation, loneliness and confusion contributed to an initial deterioration in his mental health. With no outlet to reveal or discuss how he was feeling in his work place, but, paradoxically, a pressure to demonstrate strength of character and a positive frame of mind, Vincent found it increasingly difficult to cope mentally. Over time, this resulted in him losing his sense of future perspective - something that, in turn, produced the conditions for the internalisation of depression (Roderick and Gibbons, 2015).

Whilst there is a body of work that argues that the pressures placed upon elite athletes means that they may be more likely to be exposed to mental illness than members of the general population (Beable, et al, 2017; Gulliver et al, 2015; Malcolm and Scott, 2012; Mummery, 2005; Rice, et al, 2016; Wood et al, 2017), Vincent's case shows that his exposure to the risks of developing mental illness may have been even greater still, given the additional challenges that he had to face moving from one country to another to ply his trade. Such a line of argument would fit with the findings of other studies situated outside of sport where migration has been identified as creating the conditions for the development of mental illness (Bhugra and Becker, 2005; Bhugra et al, 2014; Mendenhall, 2016; Sharma and Jaswal, 2006). More specifically, Vincent's case highlights the importance of managing the international transfers of foreign players effectively. Transfers are often periods of uncertainty for all players. For players moving overseas to unfamiliar social and cultural environments, this uncertainty can often be coupled with a range of additional challenges that, if not 
managed effectively, could, as Vincent's case shows, have negative consequences for their mental health. As such, appropriately structured and specifically tailored social and occupational support should be seen as crucial for migrants during these periods of international transfer.

Increasingly, and in many working environments, employees are being encouraged to talk about and discuss their mental health. Organisations such as Mind have worked hard to break the stigma attached with mental illness in the work place. Unfortunately, as Vincent's case shows, professional football in England does not appear (yet, at least) to be a working environment in which players feel they can openly discuss their mental health or any challenges that they may be facing as a consequence of deterioration in it (Drawer and Fuller, 2002; Gouttebarge and Sluiter, 2014). As such, clubs should consider creating 'safe spaces' where players can discuss their mental health with a suitably qualified professional in confidence and be treated, if necessary, without risk of stigmatisation. Vincent argued that he would have felt much more comfortable discussing his mental health, if he knew that his identity would be protected.

Vincent argued on a number of occasions that he was not an isolated case in respect of the challenges he faced or the depression he suffered. Indeed, he would often recall stories of other migrant players who had suffered the same or similar issues during their careers. Vincent was of the opinion that at least half of all migrant players that he had encountered were affected in a similar way to him. Like him, the risk of stigmatisation left these players feeling unable to reveal or discuss the ways in which the challenges of migration were affecting their mental health, and, as a consequence, they "suffered in silence". What these players' stories, and the recommendations made in this paper, highlight is the need for a shift in support at clubs from one that is predominantly focussed on performance, to one that includes a focus on mental health as well. 


\section{References}

Agergaard, S. and Ryba, T. (2014). Migration and career transitions in professional sports: Transnational athletic careers in a psychological and sociological perspective. Sociology of Sport Journal, 31(2), 228-247.

American Psychiatric Association. (2013). Diagnostic and Statistical Manual of Mental Disorders (Fifth Edition). Washington: American Psychiatric Association.

Bauman, N. J. (2017). The stigma of mental health in athletes: are mental toughness and mental health seen as contradictory in elite sport? British Journal of Sports Medicine, 50, 135-136.

Beable, S., Fulcher, M., Hamilton, B and Chun-Lee, A. (2017). SHARP - Sports Mental Health Awareness Project: Prevalence and Risk Factors of Depressive Symptoms and Life Stress in Elite Athletes. British Journal of Sports Medicine, 51, 293.

Bhugra, D. and Becker, M. (2005). Migration, cultural bereavement and cultural identity. World Psychiatry, 4(1), 18-24.

Bhugra, D., Gupta, S., Schouler-Ocak, M., Graeff-Calliess, I., Deakin, N., Qureshi, A., Dales, J., Moussaoui, D., Kastrup, M., Tarricone, I., Till, A., Bassi, M. and Carta, M. (2014). EPA Guidance mental health care of migrants. European Psychology, 29(2), 107-115.

Bourke, A. (2003). The dream of being a professional soccer player: Insights on career development options of young Irish players. Journal of Sport and Social Issues, 27(4), 399-419.

Braun, V. and Clarke, V. (2006). Using thematic analysis in psychology. Qualitative Research in Psychology, 3(2), 77-101.

Braun, V. and Clarke, V. (2019). Reflecting on reflexive thematic analysis. Qualitative Research in Sport, Exercise and Health, 11(4), 589-597.

Carless, D. and Douglas, K. (2019). In it for The Long Run: Researching Mental Health and Illness. In M. Atkinson (ed.) Sport, Mental Illness and Sociology. Bingley: Emerald Publishing, pp.177-192.

Carter, T. (2011). In Foreign Fields: The politics and experiences of transnational sport migration. London: Pluto Press.

DeHaney D (2013) Football's Suicide Secret [Television Programme]. London: BBC.

Drawer, S. and Fuller, C. (2002). Perceptions of retired professional soccer players about the provision of support services before and after retirement. British Journal of Sports Medicine, 36(1), 33-38.

Elliott, R. (2014). 'Brits abroad: A case study analysis of three British footballers migrating to the Hungarian Soproni Liga, Soccer and Society', 15(4), 517-534. 
Elliott, R. (2015). 'Chasing the ball: The motivations, experiences and effects of migrant professional footballers'. In R. Elliott \& J. Harris (eds.) Football and Migration: Perspectives, places, players. London: Routledge, pp.21-35.

Frank, R., Nixdorf, I. and Beckmann, J. (2015). Depression among Elite Athletes: Prevalence and Psychological Factors. Deutsche Zeitschrift für Sportmedizin [German Journal of Sports Medicine], 64, 320-326.

Fry, J. and Bloyce, D. (2017). 'Life in the travelling circus': A study of loneliness, work stress, and money issues in touring professional golf. Sociology of Sport Journal, 34(2), 148-159.

Goffman, E. (1959). The Presentation of Self in Everyday Life. London: Penguin.

Goffman, E. (1963). Stigma: Notes on the Management of Spoiled Identity. Englewood Cliffs: Prentice Hall.

Gouttebarge, V. and Sluiter, J. (2014). Medical examinations undertaken by Dutch professional football clubs. Occupational Medicine, 64(1), 13-16.

Gouttebarge, V., Frings-Dresen, M. and Sluiter, J. (2015). Mental and psychosocial health among current and former professional footballers. Occupational Medicine, 65(3), 190-196.

Grandey, A. (2000). Emotion Regulation in the Workplace: A New Way to Conceptualize Emotional Labor. Journal of Occupational Health Psychology, 5(1), 95-110.

Gulliver, A., Griffiths, K., Mackinnon, A., Batterham, P. and Stanimirovic, R. (2015). The mental health of Australian elite athletes. Journal of Science and Medicine in Sport, 18, 255-261.

Hewitt, J. (2007). Ethical components of researcher-researched relationships in qualitative interviewing. Qualitative Health Research, 17(8), 1149-1159.

Hochschild, A. (1983). The Managed Heart: Commercialization of Human Feeling. Berkeley: University of California Press.

Hughes, L., \& Leavey, G. (2012). Setting the bar: athletes and vulnerability to mental illness. British Journal of Psychiatry, 200(2), 95-96.

Jones, G., Hanton, S. and Connaughton, D. (2002). What is this thing called mental toughness? An investigation of elite sports performers. Journal of Applied Sport Psychology, 14, 205-218.

Karp, D. (2017). Speaking of Sadness: Depression, Disconnection and the Meaning of Illness. Oxford: Oxford University Press.

Kelly, S. (2015). The migration of Irish professional footballers: the good, the bad and the ugly. In R. Elliott and J, Harris (eds.) 'Football and Migration: Perspectives, places, players'. London: Routledge, pp. 76-92. 
Lee-Sinden, J. (2010). The normalization of emotion and the disregard of health problems in elite amateur sport. Journal of Clinical Sport Psychology, 4, 241-256.

Lee-Sinden, J. (2012). The sociology of emotion in elite sport: Examining the role of normalization and technologies. International Review for the Sociology of Sport, 48(5), 613-628.

Magee. J., \& Sugden, J. (2002). "The world at their feet": Professional football and international labour migration. Journal of Sport and Social Issues, 26(4), 421437.

Maguire, J. (1996). Blade Runners: Canadian Migrants, ice hockey and the global sports process. Journal of Sport and Social Issues, 21(3), 335-360.

Maguire, J. and Stead, D. (1998). Border Crossings: Soccer Labour Migration and the European Union. International Review for the Sociology of Sport, 33(1), 59-73.

Malcolm, D. and Scott, K. (2012). Suicide, sport and medicine. British Journal of Sports Medicine, 46, 1092-1093.

McMahon, J. and Penney, D. (2011). Empowering swimmers and their bodies in and through research. Qualitative Research in Sport, Exercise and Health, 3(2), 130-151.

Mendenhall, E. (2016). The "cost" of health care: Poverty, depression, and diabetes among Mexican immigrants in the United States. In A. Kohrt and E. Mendenhall (eds). Global Mental Health: Anthropological Perspectives. London: Routledge, pp.205-220.

Molnar, G. (2010). Rediscovering Hungarianness: The case of elite Hungarian footballers. In P. Dine \& S. Crosson (eds.) Sport, Representation and Evolving Identities in Europe. Oxford: Peter Lang, pp.239-262.

Mummery, K. (2005) Essay: Depression in Sport. The Lancet, 366, S36-S37.

National Institute for Health Research (2013). Good Practice Guidance for Involving People with Experience of Mental Health Problems in Research. London: Mental Health Research Network.

Nesti, M. (2010). Psychology in Football: Working with elite and professional players. London: Routledge.

Palmer, C. (2019). Drugs, Alcohol, and Addiction in Sport. In M. Atkinson (ed.) Sport, Mental Illness and Sociology. Bingley: Emerald Publishing, pp.111-126.

Pike, E. (2019). Mental Health Stigma. In M. Atkinson (ed.) Sport, Mental Illness and Sociology. Bingley: Emerald Publishing, pp.9-22.

Pollard, C. (2015). What is the Right Thing to Do: Use of a Relational Ethic Framework to Guide Clinical Decision-Making. International Journal of Caring Sciences, 8(2), 362-368. 
Rice, S., Purcell, R., Silva, S., Mawren, D., McGorry, P. and Parker, A. (2016). The Mental Health of Elite Athletes: A Narrative Systematic Review. Sports Medicine, 46(9), 1333-1353.

Richardson, D., Littlewood, D. and Nesti, M. (2012). An examination of the migratory transition of elite young European soccer players to the English Premier League. Journal of Sports Sciences, 30(15), 1605-1618.

Roderick, M. (2006a). The Work of Professional Football: A labour of love. London: Routledge.

Roderick, M. (2006b). A very precarious profession: Uncertainty in the working lives of professional footballers. Work, Employment and Society 20(2): 245-265.

Roderick, M. (2012). Domestic moves: An exploration of intra-national labour mobility in the working lives of professional footballers. International Review for the Sociology of Sport, 48(4), 387-404.

Roderick, M. and Gibbons, B. (2015). 'To thine own self be true: Sports work, mental illness and the problem of authenticity. In: J. Baker, P., Safai, and J. FraserThomas. (eds). Health and Elite Sport: Is High Performance Sport a Healthy Pursuit? London: Routledge, pp.149-162.

Sharma, S. and Jaswal, S. (2006). Migration and magnitude of psychological distress. Journal of Social Sciences, 12(3), 225-229.

Stead. D, and Maguire. J, (2000). "Rite de Passage or Passage to Riches?": The Motivation and Objectives of Nordic/Scandinavian Players in English League Soccer'. Journal of Sport and Social Issues, 24(1), 36-60.

Ward, C., Bochner, S. and Furnham, A. (2001) The Psychology of Culture Shock. Hove: Routledge.

Weedon, G. (2012). 'Glocal boys': Exploring experiences of acculturation amongst migrant youth footballers in Premier League academies'. International Review for the Sociology of Sport, 47(2), 200-216.

Wood, S., Harrison, L. and Kucharska, J. (2017). Male professional football players' experiences of mental health difficulties and help-seeking. The Physician and Sportsmedicine, 45(2), 120-128.

World Health Organization. (2012). Risks to mental health: An overview of vulnerabilities and risk factors. Geneva: World Health Organization. 